\title{
PERBEDAAN PERFORMA MENGAJAR ANTARA DOSEN KEPERAWATAN PADA PERGURUAN TINGGI NEGERI DAN SWASTA DI PROVINSI JAWA TENGAH, INDONESIA
}

\author{
DIFFERENCES IN THE TEACHING PERFORMANCE BETWEEN \\ NURSING LECTURERS AT \\ PUBLIC AND PRIVATE COLLEGES IN CENTRAL JAVA PROVINCE, \\ INDONESIA
}

Yektiningtyastuti

Dosen Program Profesi Ners Sekolah Tinggi Ilmu Kesehatan Al-Irsyad Al-Islamiyyah Cilacap e-mail:yningtyastuti@gmail.com / yektiningtyastuti@stikesalirsyadclp.ac.id

\section{INFO}

ARTIKEL

Kata Kunci :

Performa

mengajar, dosen

keperawatan,

negeri, swasta

Key Word:

Teaching

Performance,

Nursing lecturers,

Public, Private

\begin{abstract}
ABSTRAK/ABSTRACT
Keterampilan profesional dan kompetensi dosen dapat dilihat dari performa mengajar. Performa mengajar mengacu pada pengetahuan, keterampilan, dan bahkan kemampuan yang harus dimiliki dan dapat ditunjukkan oleh para dosen dalam kegiatan mengajar mereka.

Penelitian ini dilakukan untuk mengetahui performa mengajar dosen keperawatan di ruang kelas dan di wahana klinik, baik di Perguruan Tinggi Negeri maupun Swasta di Provinsi Jawa Tengah, Indonesia. Penelitian ini merupakan penelitian kuantitatif non-eksperimental dengan metode deskriptif komparatif. Responden terdiri dari 134 dosen keperawatan.

Data penelitian berasal dari jawaban responden terhadap satu paket kuesioner performa mengajar, yang terdiri dari 33 item pertanyaan. Studi pendahuluan dilakukan dengan mendistribusikan kuesioner kepada 37 dosen keperawatan di dua program studi keperawatan dan memperoleh skor Alpha Cronbach 0,920. Data penelitian dikumpulkan secara pribadi oleh peneliti dari dua program studi keperawatan di perguruan tinggi negeri dan lima program studi keperawatan di perguruan tinggi swasta. Analisa data yang digunakan adalah uji-t independent.

Hasil penelitian menunjukkan bahwa tidak ada perbedaan yang signifikan dalam performa mengajar di ruang kelas antara dosen keperawatan pada perguruan tinggi negeri dan swasta $(t$ hitung $=$ $1,25844<t$ tabel $=1,96)$. Dalam hal pembelajaran di wahana klinik, didapatkan ada perbedaan yang signifikan dalam performa mengajar antara dosen keperawatan pada perguruan tinggi negeri dan swasta $(t$ hitung $=2,72417>t$ tabel $=1,96$ )
\end{abstract}

The professional skills and abilities of teacher competence can be seen from the performance of teaching. Teaching performance refers to the knowledge, skills, and even abilities which beginning teachers should have and be able to demonstrate in their activities.

The study was conducted to determine the teaching performance of 
nursing lecturers in the classroom and clinical area; both in Public and Private Nursing Colleges in Central Java Province, Indonesia. The study made use of a non-experimental descriptive comparative method of quantitative research. The study had 134 nursing lecturers.

The basis of the data came from the respondents' answers to the one package of teaching performance questionnaire, which consisted of 33 items. A pilot study was conducted by distributing questionnaires to 37 nursing lecturers in two nursing colleges and obtained a score of Alpha Cronbach 0.920 . The researcher personally collected data form nursing program study in two public universities and four nursing program study in private nursing colleges. To analyze the data gathered, t-test was utilized.

The results of the study show that there is no significant difference between the self-assessed teaching performance of nursing faculty respondents in terms of classroom setting in the public and private colleges (the computed $t=1.25844<t$ table $=1.96$ ). In terms of clinical area setting, there is a significant difference between the self-assessed teaching performance of nursing faculty respondents in terms of the clinical area setting in the government and private colleges (the computed $t=2.72417>t$ table $=1.96$ ).

\section{A. PENDAHULUAN}

Berdasarkan data dari Direktorat Jenderal Pendidikan Tinggi Republik Indonesia terdapat 218 lembaga pendidikan keperawatan di semua provinsi di Indonesia, dengan jumlah total dosen keperawatan adalah 2.920 orang dengan kualifikasi Doktor Keperawatan, Spesialis Keperawatan, Magister Keperawatan, dan Sarjana Keperawatan-Ners (Ditjen DIKTI, 2014). Di Provinsi Jawa Tengah yang mencakup 29 kabupaten dan 6 kota, terdapat 28 lembaga pendidikan Program Studi Keperawatan yang berada di bawah Perguruan Tinggi Negeri dan Swasta, dengan berbagai variasi sumber daya (AIPNI-AINEC, 2012).

Berdasarkan pengamatan dan evaluasi dari stakeholder, secara umum lulusan baru program keperawatan dinilai masih belum siap untuk bekerja dan belum memiliki keterampilan awal yang memenuhi standar kompetensi sebagai staf perawat pemula. Dalam dunia pendidikan diakui bahwa dosen sangat menentukan lulusan yang akan dihasilkan oleh suatu lembaga pendidikan. Kompetensi dari dosen juga menentukan pencapaian kompetensi dari mahasiswa yang diajar dan dibimbingnya. Dosen memiliki peran penting dalam proses pembelajaran untuk memastikan mahasiswa dapat mencapai kompetensi secara optimal.

Dosen adalah orang yang paling bertanggung jawab untuk mengajar, mendidik dan membimbing praktik sehingga mahasiswa dapat mencapai tujuan akhir dari proses pendidikan dengan baik (Wicaksi, 2010). Oleh karena itu, dosen harus memiliki 
performa mengajar yang baik agar dapat mentransfer pengetahuan, keterampilan dan nilai-nilai dengan baik.

Dengan kemajuan ilmu pengetahuan, teknologi dan media informasi terjadi perubahan kompetensi dan intensionalitas untuk meningkatkan kapasitas, keterampilan dan kemampuan mengajar. Empat kompetensi mengajar yang harus dikuasai dosen, yaitu kompetensi teknis, metodologis, sosial dan partisipatif, yang masing-masing terkait satu sama lain (Gálvez Suarez \& Milla Toro, 2018).

Performa mengajar berkaitan dengan kemampuan pengajar untuk menunjukkan instruksi di kelas ataupun di laboratorium. Performa mengajar dipahami sebagai praktik pedagogik yang dapat diamati dan terwujud dengan sendirinya ketika guru mengungkapkan kompetensinya dan berkaitan dengan prestasi belajar yang diharapkan, yaitu intensionalitas pendidikan dan pelaksanaan tugas yang diberikan, pada gilirannya tergantung pada perbedaannya. faktor-faktor yang berkaitan dengan kualitas dan pelatihan awal guru guna mencapai tingkat keunggulan dalam pendidikan (Gálvez Suarez \& Milla Toro, 2018). Performa mengajar mencakup empat komponen kompetensi:

1). kompetensi profesional, 2). kompetensi sosial, 3). kompetensi kepribadian, dan 4). Kompetensi pedagogik (Sufiati \& Afifah, 2019).
Dosen keperawatan dalam mengajar juga harus menerapkan berbagai kompetensi mengajar tersebut, baik ketika mengajar di ruang kelas maupun di wahana klinik. Selain dipengaruhi oleh berbagai kompetensi tersebut, sumber daya dan fasilitas yang dimiliki oleh perguruan tinggi, dan wahana praktik yang digunakan dalam proses pembelajaran keperawatan juga sangat menentukan kompetensi lulusan pendidikan keperawatan.

Berdasarkan hal tersebut, maka penelitian ini dilakukan, dengan tujuan tujuan untuk mengetahui gambaran performa mengajar dosen keperawatan, baik di perguruan tinggi milik pemerintah maupun swasta, serta menganalisa adakah perbedaan performa mengajar antara dosen keperawatan pada perguruan tinggi negeri dan swasta.

\section{B. METODE}

Penelitian ini adalah penelitian kuantitatif non eksperimental dengan desain penelitian deskriptif komparatif. Penelitian kuantitatif merupakan pendekatan penelitian yang mewakili paham positivism. Penelitian kuantitatif biasanya menggunakan desain eksplanasi, di mana objek telaahan penelitian eksplanasi (explanatory research) adalah untuk menguji hubungan antar-variabel yang dihipotesiskan (Mulyadi, 2013). 
Penelitian deskriptif (descriptive research) merupakan penelitian yang memberi gambaran yang lebih jelas tentang situasi-situasi sosial. Penelitian ini biasa disebut juga penelitian taksonomik (taxonomic research), yang dimaksudkan untuk eksplorasi dan klarifikasi mengenai sesuatu fenomena atau kenyataan sosial, dengan jalan mendeskripsikan sejumlah variabel yang berkenaan dengan masalah dan unit yang diteliti (Mulyadi, 2013).

Populasi dari penelitian ini adalah seluruh dosen program studi keperawatan di wilayah Provinsi Jawa Tengah. Sampel penelitian adalah dosen keperawatan dari dua (2) program studi keperawatan di Perguruan Tinggi Negeri dan lima (5) program studi keperawatan di Perguruan Tinggi Swasta yang dipilih secara acak sederhana (simple random sampling) dari 28 progran studi keperawatan yang ada di Provinsi Jawa Tengah. Kriteria inklusi untuk perguruan tinggi yang diambil adalah memiliki program studi keperawatan, memiliki nisbah dosen: mahasiswa yang sebanding, mahasiswa pendaftar tahun terakhir yang memadai, keragaman aal dan latar belakang budaya mahasiswa, dan memiliki dosen tetap penuh waktu maupun paruh waktu.

Responden adalah dosen keperawatan penuh waktu dan paruh waktu, yang mengajar di kelas maupun di wahana klinik. Responden penelitian terdiri dari 134 dosen keperawatan, yang meliputi: 50 dosen keperawatan dari Perguruan Tinggi Negeri dan 84 dosen keperawatan dari Perguruan Tinggi Swasta.

Kuesioner penelitian berupa satu set kuesioner penilaian mandiri (self assesment) performa mengajar dari peneliti. Sebelum kuesioner digunakan dalam penelitian, validitas isi kuesioner telah dilakukan oleh enam (6) pakar pendidikan. Selanjutnya dilakukan uji validitas dan reliabilitas pada dua program studi keperawatan melalui studi percontohan yang melibatkan 37 dosen keperawatan. Kedua program studi keperawatan tersebut tidak dimasukkan sebagai responden penelitian untuk mencegah bias pengujian. Hasil uji validitas dan reliabilitas kuesioner diperoleh 33 dari 40 item kuesioner valid (koefisien reliabilitas Cronbach $=0,920$ ) . Kuisioner ini menggunakan skala lima poin Likert untuk mengukur sejauh mana responden menilai performa mengajarnya, dengan pilihan jawaban: selalu, sering, jarang, kadag-kadang, dan tidak pernah. Instrumen penilaian performa mengajar dosen di kelas mencakup 15 item pernyataan, sedangkan untuk performa mengajar di wahana klinik terdiri dari 18 item pernyataan. Interpretasi penilaian dari hasil skor keseluruhan item kuesioner performa mengajar adalah: 


\begin{tabular}{|c|c|}
\hline $4.51-5.00$ & Sangat bagus (excellent) \\
\hline $3.51-4.50$ & $\begin{array}{l}\text { Sangat memuaskan (very } \\
\text { satisfactory) }\end{array}$ \\
\hline $2.51-3.50$ & $\begin{array}{l}\text { Memuaskan } \\
\text { (satisfactory) }\end{array}$ \\
\hline $1.51-2.50$ & $\begin{array}{l}\text { Kurang memuaskan (fair } \\
\text { satisfactory) }\end{array}$ \\
\hline $0.01-1.50$ & $\begin{array}{l}\text { Perlu perbaikan (needs } \\
\text { improvement) }\end{array}$ \\
\hline
\end{tabular}

Pengumpulan data dilakukan langsung oleh peneliti dengan mengunjungi dan menyebarkan kuesioner di tujuh perguruan tinggi asal responden setelah mendapatkan ijin dari para pimpinan Perguruan Tinggi. Setelah data terkumpul, peneliti melakukan statistik pengolahan data melalui komputer untuk mendapatkan nilai rerata (mean) dari variabel yang diteliti. Uji independent t-test digunakan untuk menngalisis perbedaan nilai rerata hasil penelitian antara dua kelompok responden.

\section{HASIL}

Hasil penelitian disajikan menjadi empat bagian, yaitu: 1). Gambaran karakteristik responden. 2). Gambaran performa mengajar dosen keperawatan di perguruan tinggi negeri, 3). Gambaran performa mengajar dosen keperawatan di perguruan tinggi swasta, 4). Perbedaan performa mengajar antara dosen keperawatan di perguruan tinggi negeri dan swasta.

\section{1) Karakteristik Responden}

Berdasarkan kriteria inklusi yang ditetapkan oleh peneliti, karakteristik responden dari perguruan tinggi negeri $(\mathrm{n}=50)$ adalah sebagai berikut: sebagian besar (52\%) responden berusia 26 - 35 tahun, jabatan fungsional dosen paling banyak (42\%) adalah lektor, pendidikan terakhir sebagian besar (86\%) adalah magister/spesialis, dan paling banyak (42\%) memiliki pengalaman mengajar 5 - 10 tahun. Sedangkan karakteristik reponden dari perguruan tinggi swata $(n=84)$ adalah sebagai berikut: paling banyak (44\%) responden berusia 26 35 tahun, paling banyak (38\%) belum memiliki jabatan fungsional (tenaga pengajar), pendidikan terakhir sebagian besar (61\%) adalah magister/spesialis dan paling banyak (35\%) memiliki pengalaman mengajar 5 - 10 tahun.

\section{2) Gambaran performa mengajar} dosen keperawatan di Perguruan Tinggi Negeri

a. Performa mengajar di kelas

Berdasarkan 15 item pernyataan dalam penilaian mandiri (self assesment) performa mengajar di kelas diperoleh data rerata hasil (overall mean) $=$ 4.30 atau dalam kategori sangat 
memuaskan. Item pernyataan dengan rerata tertinggi (mean = 4.72) ditemukan pada item pernyataan nomor 1 yaitu "Saya memandu mahasiswa terkait tujuan spesifik pembelajaran." Sedangkan rerata terendah jawaban (mean $=$ 3.52) ditemukan pada item pernyataan nomer 11 yaitu "Saya mengidentifikasi masalah-masalah perilaku yang ditemukan di kelas, seperti intimidasi, perkelahian dll."

b. Performa mengajar di wahana klinik Berdasarkan 18 item pernyataan dalam penilaian mandiri (self assesment) performa mengajar di wahana klinik diperoleh data rerata hasil (overall mean) $=4.37$ atau dalam kategori sangat memuaskan. Item pernyataan dengan rerata tertinggi $($ mean $=4.66)$ ditemukan pada item pernyataan nomor 1 yaitu "Saya menggunakan Rencana Program Pembelajaran Klinik sesuai dengan tujuan spesifik." Sedangkan rerata terendah jawaban (mean $=$ 3.98) ditemukan pada item pernyataan nomer 8 yaitu "Saya menyediakan waktu ekstra untuk mahasiswa yang tidak dapat memenuhi tugas dan kompetensi klinik yang diharapkan.”
3) Gambaran performa mengajar dosen keperawatan di Perguruan Tinggi Swasta

a. Performa mengajar di kelas

Berdasarkan kuesioner penilaian mandiri (self assesment) performa mengajar di kelas pada responden dari Perguruan Tinggi Swasta diperoleh data rerata hasil (overall mean) $=\mathbf{4 . 4 4}$ atau dalam kategori sangat memuaskan. Item pernyataan dengan rerata tertinggi (mean $=$ 4.74) ditemukan pada item pernyataan nomor 2 yaitu "Saya menyediakan petunjuk pembelajaran yang efektif sesuai syllabus dan melalui bacaan tambahan." Sedangkan rerata terendah jawaban $($ mean $=3.96)$ ditemukan pada item pernyataan nomer 11, sama dengan rerata terendah pada Perguruan Tinggi Negeri, yaitu pernyataan "Saya mengidentifi-kasi masalahmasalah perilaku yang ditemukan di kelas, seperti intimidasi, perkelahian dll."

b. Performa mengajar di wahana klinik

Berdasarkan kuesioner penilaian mandiri (self assesment) performa mengajar di wahana 
klinik pada responden dari Perguruan Tinggi Swasta diperoleh data diperoleh data rerata hasil $($ overall mean $)=4.54$ atau dalam kategori sangat bagus. Item pernyataan dengan rerata tertinggi $($ mean $=4.81)$ ditemukan pada item pernyataan nomor 13 yaitu "Saya mempertahankan hubungan yang harmonis dengan semua staff dan pimpinan di wahana klinik." Sedangkan rerata terendah jawaban $($ mean $=4.05)$ ditemukan pada item pernyataan nomer 8 yaitu "Saya menyediakan waktu ekstra untuk mahasiswa yang tidak dapat memenuhi tugas dan kompetensi klinik yang diharapkan.”

\section{4) Perbedaan performa mengajar antara dosen keperawatan di perguruan tinggi negeri dan swasta}

Berdasarkan analisis uji beda dua rerata dengan menggunakan independent $t$ test untuk mengetahui perbedaan penilaian mandiri performa mengajar di kelas antara dosen keperawatan di Perguruan Tinggi Negeri dan Swasta diperoleh hasil $t$ hitung $=1.25844$, lebih kecil dari $t$ tabel $=1.96$ (pada $\alpha=0.05)$, sehingga hypothesis null (Ho) diterima. Hal ini menunjukkan bahwa tidak ada perbedaan yang signifikan penilaian mandiri performa mengajar di kelas antara dosen keperawatan di Perguruan Tinggi Negeri dan Swasta.

Sedangkan hasil independent $t$ test untuk mengetahui perbedaan penilaian mandiri performa mengajar di wahana klinik antara dosen keperawatan di Perguruan Tinggi Negeri dan Swasta diperoleh hasil $t$ hitung $=2.72417$, lebih besar dari $t$ tabel $=1.96($ pada $\alpha$ $=0.05)$, sehingga hypothesis null $(\mathrm{Ho})$ ditolak. Hal ini berarti bahwa ada perbedaan yang signifikan penilaian mandiri performa mengajar di wahana klinik antara dosen keperawatan di Perguruan Tinggi Negeri dan Swasta.

\section{PEMBAHASAN}

Hasil penelitian menunjukkan bahwa tidak ada perbedaan yang signifikan penilaian mandiri performa mengajar di kelas antara dosen keperawatan di Perguruan Tinggi Negeri dan Swasta. Hasil penelitian ini menyiratkan bahwa kemampuan atau kompetensi dosen keperawatan untuk menciptakan suasana dan komunikasi antara dosen dan mahasiswa dalam pembelajaran di kelas, antara antara dosen keperawatan di pemerintah dan di sekolah swasta adalah sama yaitu pada level sangat memuaskan. Hasil penilaian mandiri performa mengajar dosen keperawatan pada level sangat memuaskan dapat dipahami, karena latar belakang pendidikan dosen 
keperawatan baik di Perguruan Tinggi Negeri maupun Swasta sebagian besar adalah Magister atau Spesialis Keperawatan.

Berdasarkan penelitian yang dilakukan oleh Prayitno dengan judul Pengaruh Tingkat Pendidikan dan Pengalaman Mengajar Terhadap Kompetensi Profesional Guru Pada Mata Pelajaran IPS di SD SeKecamatan Buntu Batu Kabupaten Enrekang, menyebutkan bahwa ada pengaruh positif yang signifikan antara tingkat pendidikan terhadap kompetensi profesional guru ( $\mathrm{t}$ hitung $>\mathrm{t}$ tabel yakni 2.081 > 1.690) (Prayitno, 2019).

Sedangkan untuk performa mengajar di wahana klinik, hasil penelitian menunjukkan bahwa ada perbedaan yang signifikan antara penilaian mandiri performa mengajar di wahana klinik antara dosen keperawatan di Perguruan Tinggi Negeri dan Swasta. Hasil penelitian ini menyiratkan bahwa kemampuan atau kompetensi dosen keperawatan untuk menciptakan suasana, komunikasi serta proses pembelajaran antara dosen dan mahasiswa di wahana klinis antara dosen keperawatan di Perguruan Tinggi Negeri dan Swasta berbeda.

Jika dilihat dari rerata (mean) skor jawaban dosen keperawatan dalam hal performa mengajar di wahana klinik, ditemukan bahwa rerata (mean) skor jawaban dosen keperawatan di Perguruan Tinggi Swasta adalah 0,17 poin lebih tinggi dari rerata (mean) skor jawaban dosen keperawatan di Perguruan Tinggi Negeri.

Berdasarkan karakteristik pengalaman mengajar dosen keperawatan di Perguruaan Tinggi Swasta, diperoleh data bahwa $15.7 \%$ berpengalaman $>20$ tahun mengajar, $21.7 \%$ berpengalaman $16-20$ tahun mengajar, $24.6 \%$ berpengalaman mengajar 11 - 15 tahun, dan 32\% memiliki pengalaman mengajar $5-10$ tahun. Sedangkan sebaran pengalaman mengajar dosen keperawatan di Perguruan Tinggi Negeri adalah 8\% berpengalaman > 20 tahun mengajar, $20 \%$ berpengalaman $16-20$ tahun mengajar, 30\% berpengalaman mengajar 11 - 15 tahun, dan $42 \%$ memiliki pengalaman mengajar 5-10 tahun.

Performa mengajar di wahana klinik sangat dipengaruhi oleh banyak dan lamanya pengalaman mengajar di tatanan klinik, karena pembelajaran di klinik membutuhkan art dan pengalaman. Menurut (Ross, 2014), mengajar adalah seni karena, yang terbaik, itu adalah kinerja estetika yang kreatif dan orisinal, bergantung pada situasi, dan berdasarkan pada ekspresi pribadi dan penilaian individu-individu yang berbakat. Konsep pengajaran klinik ini adalah sangat menarik, dan tidak diragukan lagi akan beresonansi dengan pengalaman terbaik dari banyak para pengajar klinik, tetapi diduga hanya sedikit yang akan 
mengklaim bahwa semua pengajaran mereka mencapai standar tersebut.

Perbedaan lama waktu dan banyaknya pengalaman mengajar sangat mungkin mempengaruhi performa mengajar dosen keperawatan di wahana klinik. Pengalaman mengajar sebagian besar responden dosen keperawatan di Perguruan Tinggi Swasta lebih lama dibandingkan dengan dosen keperawatan di Perguruan Tinggi Negeri ini disebabkan karena lima dari lima Perguruan Tinggi Swasta yang dijadikan sampel penelitian sudah berdiri lebih awal $5-15$ tahun dibandingkan dengan berdirinya dua Perguruan Tinggi Negeri yang terlibat dalam penelitian. Oleh karenanya, para dosen keperawatan yang ada di Perguruan Tinggi Swasta memiliki pengalaman yang lebih lama dalam pembelajaran di wahana klinik.

Selain itu, tingkat kompetisi yang cukup ketat bagi Perguruan Tinggi Swasta untuk mendapatkan wahana praktik bagi mahasiswanya juga dapat mempengaruhi kemampuan adaptasi dosen-dosen keperawatan dari Perguruan Tinggi Swasta. Mereka dituntut untuk dapat menjalin kerja sama yang baik dengan berbagai tingkat rumah sakit, baik rumah sakit pemerintah dan swasta. Mereka juga menggunakan berbagai pusat layanan kesehatan, dengan fasilitas yang memadai dan bahkan wahana klinik yang memiliki fasilitas terbatas, agar mahasiswanya memperoleh kesempatan menempuh pembelajaran di klinik.
Berdasarkan hasil penelitian didapatkan bahwa item pernyataan pada performa mengajar di wahana klinik dengan rerata tertinggi $($ mean $=4.81)$ pada dosen keperawatan di Perguruan Tinggi Swasta adalah pada item nomor 13 yaitu "Saya mempertahankan hubungan yang harmonis dengan semua staff dan pimpinan di wahana klinik." Membina dan mempertahankan hubungan yang harmonis dalam berbagai tingkatan wahana klinik memungkinkan dosen keperawatan meningkatkan performa mengajar kliniknya.

Hal ini sesuai dengan hasil penelitian yang dilakukan oleh Yang and Chao, (2018) dengan judul Clinical nursing instructors' perceived challenges in clinical teaching bahwa tantagan yang dirasakan oleh instruktur klinik keperawatan dalam pembelajaran klinik adalah kebutuhan untuk membangun hubungan yang baik dan mempertahankan kerja sama dengan staf klinis, yang kadang-kadang mengarah pada dilema keseimbangan antara pengajaran klinik berkualitas dengan hubungan staf.

\section{E. KESIMPULAN DAN SARAN}

Hasil penelitian menunjukkan bahwa penilaian mandiri dosen keperawatan tentang performa mengajar di kelas, baik 
dosen dari Perguruan Tinggi Negeri maupun Swasta berada pada kategori sangat memuaskan. Sedangkan penilaian mandiri dosen keperawatan tentang performa mengajar di wahana klinik untuk dosen dari Perguruan Tinggi Negeri berada pada kategori sangat memuaskan sedangkan untuk dosen dari Perguruan Tinggi Swasta berada pada kategori sangat bagus.

Tidak terdapat perbedaan yang signifikan terkait performa mengajar di kelas antara dosen keparawatan dari Perguruan Tinggi Negeri dan Swasta. Sedangkan untuk performa mengajar di wahana klinik, ditemukan adanya perbedaan performa mengajar yang signifikan antara dosen keperawatan dari Perguruan Tinggi Negeri dan Swasta.

Hubungan yang harmonis antara dosen dengan semua staff dan pimpinan di wahana klinik merupakan hal yang penting dalam mencapai keberhasilan tujuan pembelajaran klinik serta dalam meningkatkan performa mengajar dosen di wahana klinik. Saran bagi peneliti selanjutnya adalah untuk mengembangkan hasil penelitian performa mengajar ini dengan menambahkan subyek penilitia yaitu: dari mahasiswa, teman sebaya (peer review) maupun dari pimpinan.

\section{DAFTAR PUSTAKA}

AIPNI-AINEC - Association Institusi Pendidikan Ners Indonesia, 2012, Profil keanggotaan AIPNI-AINEC.
Available at: http://www.aipniainec.com, diakses 15 Maret 2015.

Ditjen Dikti - Direktorat Jenderal Pendidikan Tinggi, (2011), Potret ketersediaan dan kebutuhan tenaga perawat. Available at: https://www.scribd.com/ doc/234840867/Potret-KetersediaanDan-Kebutuhan-Tenaga-Perawat, diakses 10 Maret 2015.

Gálvez Suarez, E. and Milla Toro, R. (2018), Teaching Performance Evaluation Model: Preparation for Student Learning within the Framework for Teacher Good Performance Performance Evaluation Model: Preparation for Student Learning within the Framework for Teacher Good Performance, Propósitos y Representaciones, 6(2), pp. 407-429. doi: 10.20511/pyr2018.v6n2.236.

Available at: http://www.scielo.org.pe/scielo.php? script $=$ sci_arttext\&pid $=$ S230779992018000200009\&lang=pt\%0Ah ttp://www.scielo.org.pe/pdf/pyr/v6n2 la09v6n2.pdf, diakses 20 Juni 2020.

Mulyadi, M. (2013). Penelitian Kuantitatif Dan Kualitatif Serta Pemikiran Dasar Menggabungkannya, Jurnal Studi Komunikasi dan Media, 15(1), p. 128. doi: 10.31445/jskm.2011. 150106. Available at: https://media.neliti.com/media/public ations/134513-ID-penelitiankuantitatif-dan-kualitatif-se.pdf, diakses 20 Agustus 2020.

Prayitno, R. (2019), Pengaruh Tingkat Pendidikan dan Pengalaman Mengajar Terhadap Kompetensi Profesional Guru Pada Mata Pelajaran IPS di SD Se-Kecamatan Buntu Batu Kabupaten Enrekang, Phinisi Integration Review, 2(1), p. 081. doi: 10.26858/pir.v2i1.8095. 
Availabel

at:

https://www.ojs.unm.ac.id/pir/article/vi ew/8095, diakses 20 Juni 2020.

Ross, M. (2014), Art in clinical teaching, Clinical Teacher, 11(5), pp. 325-326. doi: 10.1111/tct.12286. Available at: https://onlinelibrary.wiley.com/doi/epdf /10.1111/tct.12286, diakses 20 Juni 2020.

Sufiati, V. and Afifah, S. N. (2019), Peran perencanaan pembelajaran untuk performance mengajar guru pendidikan anak usia dini, Jurnal Pendidikan Anak, 8(1), pp. 48-53. doi: 10.21831/jpa.v8i1.26609. Available at: https://journal.uny.ac.id/index.php/jpa/a rticlee/view/26609, diakses 20 Agustus 2020.
Wicaksi, D. (2010). Hubungan Persepsi Mahasiswa Tentang Kinerja Dosen Dan Motivasi Belajar Dengan Prestasi Belajar Kebutuhan Dasar Manusia. Available at: http://eprints.uns.ac.id/5077/, diakses 20 Juni 2020.

Yang, C. I. and Chao, S. Y. (2018), Clinical nursing instructors' perceived challenges in clinical teaching, Japan Journal of Nursing Science, 15(1), pp. 50-55. doi: 10.1111/jjns.12167. Available at: https://onlinelibrary.wiley.com/doi/fu $\underline{11 / 10.1111 / j j n s .12167}$ diakses 20 Juni 2020.

\section{LAMPIRAN}

Tabel 1. Analisis bivariat perbedaan performa mengajar antara dosen keperawatan di perguruan tinggi negeri dan swasta di Provinsi Jawa Tengah

\begin{tabular}{l|c|c|c|c}
\hline \multicolumn{1}{c|}{ Variabel } & t hitung & t tabel & $\begin{array}{c}\text { Level of } \\
\text { significance }\end{array}$ & Decision \\
\hline Performa mengajar di kelas & 1,258 & 1,96 & 0,05 & Accept Ho \\
Performa mengejar di wahana klinik & 2,724 & 1,96 & 0,05 & Reject Ho \\
\hline
\end{tabular}

Sumber: data primer diolah, 2016 